\title{
Simulating stimulus- and TMS-induced interference in short-term memory using a model of prefrontal cortex
}

\author{
Tyler D Bancroft", William E Hockley, Philip Servos, Jeremy Hogeveen \\ From The Twenty Third Annual Computational Neuroscience Meeting: CNS*2014 \\ Québec City, Canada. 26-31 July 2014
}

Scalar short-term memory (STM) tasks are those in which the to-be-remembered property of a stimulus can be represented as a scalar quantity - for example, the frequency of a tactile vibration or an auditory pure tone, or the duration or amplitude of a stimulus. Scalar STM tasks have been studied extensively using single-cell methods [1-3], and have proven to be useful model systems for examining behavioural aspects of short-term memory [4-6] and developing computational models [7-10]. In two studies [11,12], we applied a model of prefrontal cortex [9] to experimental datasets [5,13].

In Study 1, we simulated the effects of presenting an irrelevant (distractor) stimulus to experimental subjects during the maintenance period of a vibrotactile scalar STM task by assuming the stimulus was encoded into memory, intruding into the PFC memory store. We were able to replicate previous experimental results [5], and our results also suggested that distractors were only encoded into memory on approximately $50 \%$ of trials, consistent with experimental indications that activity in sensory cortex may be inhibited during memory maintenance in order to protect the contents of memory against interference $[6,14]$.

In Study 2, we simulated a previous vibrotactile scalar STM study in which TMS was applied to somatosensory cortex during the maintenance period of the memory task, resulting in decreased performance [13]. We were able to replicate experimental results by assuming that TMS produced increased, noisy neural activity in sensory cortex, which then degraded the contents of the PFC memory store through feedforward interference.
Published: 21 July 2014

\section{References}

1. Romo R, Brody CD, Hernández A, Lemus L: Neuronal correlates of parametric working memory in the prefrontal cortex. Nature 1999, 399:470-473.

2. Romo R, Salinas E: Flutter discrimination: Neural codes, perception, memory and decision making. Nat Rev Neurosci 2003, 4:203-218.

3. Lemus L, Hernández A, Romo R: Neural encoding of auditory discrimination in ventral premotor cortex. Proc Nat Acad Sci 2009, 106:14640-14645.

4. Harris JA, Harris IM, Diamond ME: The topography of tactile working memory. J Neurosci 2001, 21:8262-8269.

5. Bancroft $T$, Servos P: Distractor frequency influences performance in vibrotactile working memory. Exp Brain Res 2011, 208:529-532.

6. Bancroft TD, Servos $P$, Hockley WE: Mechanisms of interference in vibrotactile working memory. PLOS ONE 2011, 6:e22518.

7. Machens CK, Romo R, Brody CD: Flexible control of mutual inhibition: A neural model of two-interval discrimination. Science 2005, 307:1121-1124.

8. Deco G, Rolls ET: Decision-making and Weber's law: A neurophysiological model. Eur J Neurosci 2006, 24:901-916.

9. Miller $\mathrm{P}$, Wang XJ: Inhibitory control by an integral feedback signal in prefrontal cortex: A model of discrimination between sequential stimuli. Proc Nat Acad Sci 2006, 103:201-206.

10. Verguts $\mathrm{T}$ : How to compare two quantities? A computational model of flutter discrimination. $J$ Cog Neurosci 2007, 19:409-419.

11. Bancroft TD, Hockley WE, Servos P: Irrelevant sensory stimuli interfere with working memory storage: Evidence from a computational model of prefrontal neurons. Cogn Affect Behav Neurosci 2013, 13:23-34.

12. Bancroft TD, Hogeveen J, Hockley WE, Servos P: TMS-induced neural noise in sensory cortex interferes with short-term memory storage. Front Comput Neurosci 2014.

13. Harris JA, Miniussi C, Harris IM, Diamond ME: Transient storage of a tactile memory trace in primary somatosensory cortex. J Neurosci 2002, 22:8720-8725.

14. Linke AC, Vicente-Grabovetsky A, Cusack R: Stimulus-specific suppression preserves information in auditory short-term memory. Proc Nat Acad Sci 2011, 108:12961-12966.

doi:10.1186/1471-2202-15-S1-P141

Cite this article as: Bancroft et al:. Simulating stimulus- and TMS-induced interference in short-term memory using a model of prefrontal cortex. BMC Neuroscience 2014 15(Suppl 1):P141.

\footnotetext{
* Correspondence: tbancroft@wlu.ca

Department of Psychology, Wilfrid Laurier University, Waterloo, Ontario,
} Canada, N2L 3C5 